\title{
Exploring the Utilitarian and Hedonic Value Derived from Tourism Pre-experiences with Virtual Reality: Differences Between Destinations and Accommodations
}

\author{
Carlos Flavián, Sergio Ibáñez-Sánchez ${ }^{(\bowtie)}$, and Carlos Orús \\ Faculty of Economy and Business, University of Zaragoza, Gran Vía 2, \\ 50005 Zaragoza, Spain \\ \{cflavian, sergiois, corus\}@unizar.es
}

\begin{abstract}
The tourism industry is in a convulsive situation of great uncertainty. The recovery of the sector depends on boosting digitalization processes. In this sense, virtual reality represents an essential tool that can generate added value in the customer experience. This study analyzes the impact of virtual reality tourism pre-experiences on the utilitarian and hedonic value perceived by the customer. In addition, given the heterogeneity of tourism products and offers, it is proposed that the influence of virtual reality on the dimensions of perceived value will depend on whether the product is evaluated on an attribute basis (hotels) or holistically (destinations). The results will provide interesting implications for understanding and generating tourism experiences with high added value. Particularly, these results will be helpful for tourism managers to design effective virtual reality pre-experiences according to the features of the tourism products they are promoting, fostering the corresponding hedonic/ utilitarian value in the tourist's pre-experience.
\end{abstract}

Keywords: Virtual reality $\cdot$ Perceived value $\cdot$ Hedonic and utilitarian

\section{Introduction}

During the last few years, we are witnessing how virtual reality (VR) technologies are gradually changing the way consumers interact with digital environments [8]. VR is based on the immersion of users in a computer-generated environment, in which they can navigate and possibly interact, triggering a stimulation of their senses in real time, which makes them feel present in the virtual environment displayed [7]. Its potential is reflected in recent predictions, which state that the VR industry will grow from the current $\$ 5$ billion to more than $\$ 12$ billion by 2024 [19]. Among the sectors that can benefit from its application, tourism is of particular relevance as VR can be employed to generate more tangible experiences [4]. This fact is important as tourism encompasses a wide variety of products with a strong intangible and experiential character (e.g., destinations, transportation, accommodations; [7]). The digitization of the tourism industry may be reinforced due to the pandemic caused by COVID-19. In this sense, VR may be of particular interest as it can be used to redesign the tourists' journey 
trying to overcome the current restrictions, as well as capture their attention and increase their desire to visit the tourist attraction after the pandemic [15]. These data highlight the interest in studying how VR can be applied, particularly in the field of tourism, to generate higher added value experiences for customers.

Previous research on VR in tourism has analyzed its impact on different tourism products individually (e.g., hotels [3]; destinations [22]) proving its positive effect on both cognitive (e.g., [13]) and affective (e.g., [5]) variables. However, there are no studies that have compared the effectiveness of VR considering the characteristics of tourism products, with the aim of determining whether its use is more important in one context or another [7]. Therefore, the present study has two main objectives: (1) to analyze the influence of VR on perceived value during tourism pre-experiences, adopting a utilitarian-hedonic approach [1], as well as on behavioral intentions; and (2) to determine the moderating role of the type of tourism product, considering preexperiences with destinations (more experiential products whose evaluations are made in a more holistic way; [22]) and accommodations (more concrete products whose evaluations are based on attributes and factual information; [5]). The results of the study aim to shed light on the effectiveness of VR for presenting tourism experiences and to understand how and what kind of value can be generated in this type of experiences.

\section{Literature Review}

\subsection{The Impact of VR on Perceived Value}

The use of VR represents a novel touchpoint with consumers that aims to bring more value in their experiences [4]. In this sense, viewing $360^{\circ}$ videos, which are recorded in the real environments, is gaining more and more popularity among consumer experiences with VR, and are being the subject of numerous academic works (e.g., [22]). This type of content can be viewed with devices which can vary in their level of technological embodiment, which is an inherent characteristic of any technology and is defined as the degree of integration of the device with the human body [4]. The use of embodied devices, such as VR headsets, turns technology into an extension of the senses, and facilitates the interpretation, perception and interaction with the environment surrounding the user [9]. Thus, viewing content with embodied devices allows users to achieve a higher degree of immersion in the experience and generates greater value during the experience [4].

For tourism, VR has been identified as a tool that positively influences factors of a utilitarian nature, such as the usefulness of the technology [10], attention during the experience [21], or knowledge and interest in the product displayed [13]; as well as factors of a hedonic nature, such as enjoyment [22] or positive emotions [5]. This brief review allows us to show that VR influences the two essential dimensions of the perceived value of the experience: utilitarian and hedonic [1]. For the present research, utilitarian value is studied through the reduction of uncertainty, defined as the evaluation of the chances that a certain negative event may develop and generate unknown outcomes [12]. For its part, hedonic value is analyzed based on the value derived from 
the experience, considered as a connection with the experience that produces rewarding and interesting experiences and leads to positive emotional responses [16]. In this sense, viewing a tourism product in VR with embodied devices is expected to generate higher perceived value, in both utilitarian and hedonic terms, compared to nonembodied devices:

$\mathrm{H}_{1}$ : Tourist pre-experiences with $360^{\circ}$ videos on devices with a high (versus low) level of technological embodiment positively influence (a) perceived utilitarian value and (b) perceived hedonic value.

\subsection{The Moderating Role of Product Type}

Previous literature has noted the existence of positive effects of VR in both destinations (e.g., [22]) and accommodations (e.g., [3]). However, there are no papers comparing both products simultaneously, which is interesting due to their different defining characteristics. The travel decision is complex and is composed of a series of subdecisions (e.g., destination, accommodation, transportation, attractions, and activities) that are hierarchical and sequenced, producing differences in information processing and evaluation of alternatives [11]. In this sense, the decision about a destination is made in the early stages of planning. Destinations are evaluated more holistically, with an important emotional and hedonic component [6]. On the other hand, the accommodation decision is made later in the process, and the potential tourist performs a more analytical and utilitarian processing of the information, making an evaluation of the attributes of the different alternatives [14]. The Construal Level Theory [20] could serve to explain these differences: by being taken earlier, the decision about the destination is represented in a more abstract and distant way in the mind of the consumer, who would perform a more projective and experiential evaluation; on the contrary, the decision about the accommodation, being taken at times closer to the actual realization of the trip, would be represented more closely in the mind of the traveler, who would perform a concrete evaluation of the attributes from the alternatives. Therefore, in a destination decision context, consumers would be expected to derive greater hedonic value with VR experiences, and this component of the experience would have a greater influence on their behavioral intentions; in contrast, in an accommodation decision, perceived utilitarian value would be especially benefited from VR experiences and would determine behavioral intentions:

$\mathrm{H}_{2}$ : For tourism pre-experiences with $360^{\circ}$ videos about destinations (versus accommodations), the impact of devices with a high (versus low) level of technological embodiment on hedonic value is (a) greater and (b) more influential on behavioral intentions.

$\mathrm{H}_{3}$ : For tourism pre-experiences with $360^{\circ}$ videos about accommodations (versus destinations), the impact of devices with a high (versus low) level of technological embodiment on utilitarian value is (a) greater and (b) more influential on behavioral intentions. 


\section{Methodology}

A laboratory experiment was performed to test the hypothesis. A between-subjects factorial design of 2 (device with high vs. low level of technological embodiment: VR headset vs. desktop computer) $\times 2$ (decision context: destination vs. accommodation) conditions was followed. Non-probability convenience sampling was employed, in which participants ( $n=140$; college students) had to imagine that they were going on a trip, placing them in a simulated shopping situation.

The procedure was as follows. First, a brief introduction was given to the participants, indicating certain general guidelines to be followed during the experiment, and they were randomly assigned to the experimental conditions. Next, they were given the questionnaire to answer a set of control questions (previous experience with the technology, with the destination, assessment of hotel attributes). Once this part was completed, participants were directed to their corresponding room where they viewed a $360^{\circ}$ video of a destination/accommodation with VR headset/computer. After the experience, participants completed the next part of the questionnaire which included measures of technological embodiment [5; e.g., "The employed technology is almost integrated into my body"], psychological presence [18; e.g., "I had a sense of "being there", in the displayed world,"], uncertainty reduction [17; e.g., "This experience has helped me to reduce the potential negative consequences of buying this tourism product"], experience value [16; e.g., "I felt interested in the displayed experience"], and behavioral intentions [2; "After this experience, I will try to find more information about the tourism product"]. Seven-point Likert scales were used, ranging from $1=$ "strongly disagree", to $7=$ "strongly agree".

\section{Expected Results and Discussion}

The hypotheses will be tested using the software SPSS (analyses of variance) and the PROCESS macro. The expected results will offer interesting implications, as they will reveal how VR increases consumers' perceived value in these experiences and the mechanisms that help understand this process and determine the individual's behavioral intentions. The consideration of product characteristics represents a novel contribution to the specialized literature, given the scarcity of works analyzing the comparative effect of VR technologies on user experience with different products. On a practical level, the results may help professionals to understand the effect of VR in the generation of preexperiences with higher added value, which may favor behavioral intentions. These results may be useful to recover the tourism industry after this delicate period.

\section{References}

1. Babin BJ, Darden WR, Griffin M (1994) Work and/or fun: measuring hedonic and utilitarian shopping value. J Consum Res 20(4):644-656

2. Bigne JE, Sanchez MI, Sanchez J (2001) Tourism image, evaluation variables and after purchase behavior: inter-relationship. Tour Manage 22(6):607-616 
3. Bogicevic V, Seo S, Kandampully JA, Liu SQ, Rudd NA (2019) Virtual reality presence as a preamble of tourism experience: the role of mental imagery. Tour Manage 74:55-64

4. Flavián C, Ibáñez-Sánchez S, Orús C (2019) The impact of virtual, augmented and mixed reality technologies on the customer experience. J Bus Res 100:547-560

5. Flavián C, Ibáñez-Sánchez S, Orús C (2021) Impacts of technological embodiment through virtual reality on potential guests' emotions and engagement. J Hosp Market Manag 30(1):120

6. Goossens C (2000) Tourism information and pleasure motivation. Ann Tour Res 27(2):301321

7. Guttentag DA (2010) Virtual reality: applications and implications for tourism. Tour Manage 31(5):637-651

8. Hollebeek LD, Clark MK, Andreassen TW, Sigurdsson V, Smith D (2020) Virtual reality through the customer journey: framework and propositions. J Retail Consum Serv 55:102056

9. Ihde D (1990) Technology and the Lifeworld: From Garden to Earth. Indiana University Press, Indiana

10. Israel K, Zerres C, Tscheulin DK (2019) Presenting hotels in virtual reality: does it influence the booking intention? J Hosp Tour Technol 10(3):443-463

11. Jeng J, Fesenmaier DR (2002) Conceptualizing the travel decision-making hierarchy: a review of recent developments. Tour Anal 7(1):15-32

12. Karl M (2018) Risk and uncertainty in travel decision-making: tourist and destination perspective. J Travel Res 57(1):129-146

13. Kim MJ, Lee CK, Jung T (2020) Exploring consumer behavior in virtual reality tourism using an extended stimulus-organism-response model. J Travel Res 59(1):69-89

14. Kim D, Park BJR (2017) The moderating role of context in the effects of choice attributes on hotel choice: a discrete choice experiment. Tour Manage 63:439-451

15. Kwok AO, Koh SG (2020) COVID-19 and extended reality (XR). Curr Issue Tour 24 (14):1935-1940

16. O'Brien HL, Cairns P, Hall M (2018) A practical approach to measuring user engagement with the refined user engagement scale (UES) and new UES short form. Int J Hum Comput Stud 112:28-39

17. Shim SI, Lee Y (2011) Consumer's perceived risk reduction by 3D virtual model. Int J Retail Distrib Manage 39(12):945-959

18. Slater M, Usoh M, Steed A (1994) Depth of presence in virtual environments. Presence Teleoperators Virtual Environ 3(2):130-144

19. Statista, Virtual Reality (VR) - statistics \& facts. bit.ly/3dY4OTQ. Accessed 30 July 2021

20. Trope Y, Liberman N (2010) Construal-level theory of psychological distance. Psychol Rev 117(2):440-463

21. Tussyadiah IP, Wang D, Jia CH (2017) Virtual reality and attitudes toward tourism destinations. In: Tussyadiah I, Wang D, Jia CH (eds) Information and communication technologies in tourism 2017. Springer, Cham, pp 229-239. https://doi.org/10.1007/978-3319-51168-9_17

22. Tussyadiah IP, Wang D, Jung TH, Tom Dieck MC (2018) Virtual reality, presence, and attitude change. Empirical evidence from tourism. Tour Manage 66:140-154 
Open Access This chapter is licensed under the terms of the Creative Commons Attribution 4.0 International License (http://creativecommons.org/licenses/by/4.0/), which permits use, sharing, adaptation, distribution and reproduction in any medium or format, as long as you give appropriate credit to the original author(s) and the source, provide a link to the Creative Commons license and indicate if changes were made.

The images or other third party material in this chapter are included in the chapter's Creative Commons license, unless indicated otherwise in a credit line to the material. If material is not included in the chapter's Creative Commons license and your intended use is not permitted by statutory regulation or exceeds the permitted use, you will need to obtain permission directly from the copyright holder. 